\title{
Driving force of soil microbial community structure in a burned area of Daxing'anling, China
}

\author{
Meng Meng ${ }^{1} \cdot$ Bing Wang ${ }^{1} \cdot$ Qiuliang Zhang ${ }^{1} \cdot$ \\ Yuan Tian ${ }^{1}$
}

Received: 17 May 2020 / Accepted: 1 July 2020 / Published online: 9 October 2020

(C) The Author(s) 2020

\begin{abstract}
Fires are an important factor impacting forest ecosystems of Daxing'anling and have a significant effect on soil microbial community structure. In this study, highthroughput sequencing for 16S rDNA and ITS rDNA were applied to analyze the changing characteristics and driving factors of bacterial and fungal community structures in burned areas with different fire severity. PICRUSt2 software was used to predict the functional characteristics of burned areas with different fire severity. The purpose was to unveil the responsive relationships among the structure and function of bacterial and fungal communities, fire severity, and post-disturbance restoration times. After high severity fires, the destruction of surface vegetation and loss of soil nutrients reduced the diversity and abundance of soil bacteria and fungi. The soil bacteria community structure, which was dominated by Acidobacteria, Proteobacteria, and Actinobacteria, changed to be dominated by Proteobacteria and Chloroflexi. As well, soil fungal community changed
\end{abstract}

Project funding: This research was funded by the National Key Research and Development Program of China (Grant No. 2017YFC0504003), Inner Mongolia Natural Science Foundation (No. 2018MS03049) and Young Teacher Research Fund Project of Forestry College of Inner Mongolia Agricultural University.

The online version is available at http://www.springerlink.com.

Corresponding editor: Yu Lei.

Electronic supplementary material The online version of this article (https://doi.org/10.1007/s11676-020-01229-0) contains supplementary material, which is available to authorized users.

Qiuliang Zhang

dis_coming@163.com

1 Forestry College, Inner Mongolia Agricultural University, Hohhot 010019, People's Republic of China from domination by Helotiales, Eurotiales and Russulales to domination by Archaeorhizomycetales and Helotiales. Over time, soil bacterial community was gradually restored to prefire levels 30 years after the fire. Soil fungal community changed and failed to restore to pre-fire levels after 30 years. After low/intermediate severity fires, environmental factors were relatively unchanged so that soil bacteria diversity and abundance increased, optimizing community composition. The diversity and abundance of soil fungi decreased and the community structure changed slightly. Over time, both bacterial and fungal communities were gradually restored to pre-fire levels 30 years after the fire. After fire disturbance, with increasing severity, soil carbon fixation, lignin degradation, mineralization of organic nitrogen and hydrolysis of organic phosphorus are enhanced. Denitrification is weakened. Therefore, forest fires have certain positive effects on carbon, nitrogen and phosphorus cycles where soil bacteria and fungi are involved.

Keywords Forest fire $\cdot$ Soil bacteria $\cdot$ Soil fungi $\cdot$ Highthroughput sequencing $\cdot$ Driving force

\section{Introduction}

Soil microbes have great complexity and diversity and are important for soil composition and nutrient cycling, and drivers of energy flow (Elsas and Boersma 2011) microbes play a critical role in plant growth and development, and in maintaining the productivity, functionality and stability of ecosystems (Felske et al. 2000; Kuramae et al. 2010). Since soil microbes are sensitive to changes in environment, they may be taken as indicators of soil restoration (Luo et al. 2020). 
Significant changes could result from either natural or anthropgenic disturbances to ecosystems, for which different types of soil microbes display divergent coping mechanism due to their contrasting survival characteristics and environments, thereby further changing the microbial community structure (Luo et al. 2020). Coal mining activities on the Loess Plateau have caused soil sedimentation which reduced soil bacterial diversity and resulted in significant changes in community structure (Luo et al. 2020). The removal of undergrowth vegetation caused chemical property changes in forest soils, including water contents, total nitrogen and phosphorus, hydrolyzed nitrogen, and available phosphorus, which in turn caused the reduction of relative abundance of soil bacteria of Proteobacteria, Planctomycetes, and Firmicutes, as well as a reduction in bacterial community diversity (Wu et al. 2020). Appropriate applications of nitrogen fertilizer increased the fertility of rice field soils but did not significantly change bacterial community structure (Liu et al. 2019). Fertilization in a short period increased available nutrients and soil water of a Eucalyptus forest, and the soil fungal community structure, which was dominated by Eurotiales, Archaeorhizomycetales, and Tremellales, changed to be dominated by Boletus and Eurotiales (Chen et al. 2020). When forest soils were degraded, the surface vegetation changed from trees to herbs, and the soil became more permeable but with lower nutrients such as total nitrogen and total carbon. In this study, the relative abundance of Eurotiales and Acidobacteria soil microbes increased dramatically but Basidiomycota levels were reduced significantly, indicating an obvious enhancement of microbe community diversity (Li et al. 2020).

Among various disturbances, fires have quite different effects on soil microbial community structure which are a continuous process (Villadas et al. 2019; Luo et al. 2020). Microbial communities are first directly affected by high temperatures and indirectly by changes in physical and chemical properties (Cai et al. 2014; Wang et al. 2020). Change in organic matter quantity and quality, fluctuations in carbon and nitrogen contents (Shen et al. 2013; Kaiser et al. 2016), increases in $\mathrm{pH}$ (Holden et al. 2016; Wang et al. 2016; Schmidta et al. 2019), and variations in water contents are key factors changing the microbial communities (Shigeto et al. 2008; Man et al. 2010; Rasche et al. 2011; Vries 2012). Forest fires have two forms of impacts on microbial communities (Brais et al. 2000; Wallenius et al. 2004): one, the structure and functions of microbial communities can be destroyed under high severity fires, while, low severity fires optimize the forming of microbial communities, contributing to the stability of ecosystem structure (Akburak et al. 2018; Van et al. 2019).

In Daxing'anling forest, boreal and the mixed wood species are widely distributed (Tian et al. 2018). This is a region of high fire risk. In Hulunbuir City where the study area is located, fires occurred over 600 times from 1990 to 2018. Therefore, it is necessary to study the microbial restoration characteristics of the forest soils of the Daxing'anling area after fire. High-throughput sequencing for 16S rDNA and ITS rDNA were applied to analyze the changing characteristics and relative driving factors of the soil bacterial and fungal communities in burned areas under different fire severities. PICRUSt 2 software was used to predict the functional characteristics of the soil element cycle in burned areas under different fire severity. The purpose of this study was to determine the relationship between structure and function of soil bacterial and fungal communities, the fire severity, and post-disturbance restoration time, to provide information for understand the restoration process of soil structure and function, and to propose targeted management measures.

\section{Materials and methods}

\section{Study area}

The research was located in Hulunbuir City, northwest of Daxing'anling in the northernmost part of China. It is a humid temperate zone with average annual temperatures of $-5.4{ }^{\circ} \mathrm{C}$, and average annual precipitation of $500 \mathrm{~mm}$, mainly concentrated in June to September, and average altitudes of $976.5 \mathrm{~m}$ a.s.1. It has an average $75 \%$ forest cover consisting of Larix gmelinii associated with Betula platyphylla, Populus davidiana and Pinus sylvestris (Tian et al. 2018). The study area has a high incidence of fires, over 677 fires from 1990 to 2018. Fires generally occur in May and June (Zhang et al. 2020). For this study, based on consistent site conditions, five burned blocks from the southern parts of Genhe City were selected in August 2018, where fires happened all by lightning (Table 1, Fig. S1) in May 1987, June 2003, May 2010, May 2015, and June 2018. These burned areas characterize the recovery status of the forest ecosystem after 30 years, 15 years, 8 years, 3 years and 8 weeks, respectively, following the fire.

\section{Setting of plots}

Combining the forest resource features of Daxing'anling, (evolution history, forest age, tree species and forest type), the Composite Burn Index Investigation Contents and Evaluation Criteria (Table 2), which is applicable to the study area, was prepared according to the Composite Burn Index (CBI) proposed by Key and Benson (Key and Benson 2006). The field survey was conducted in August 2018. Sixty sampling sites (over $50 \mathrm{~m}$ intervals) were randomly established in every burned area based on the CBI of all sites and classified based on fire severity index (FSI) (Table 3), which was considered the FSI classification for burned areas of 


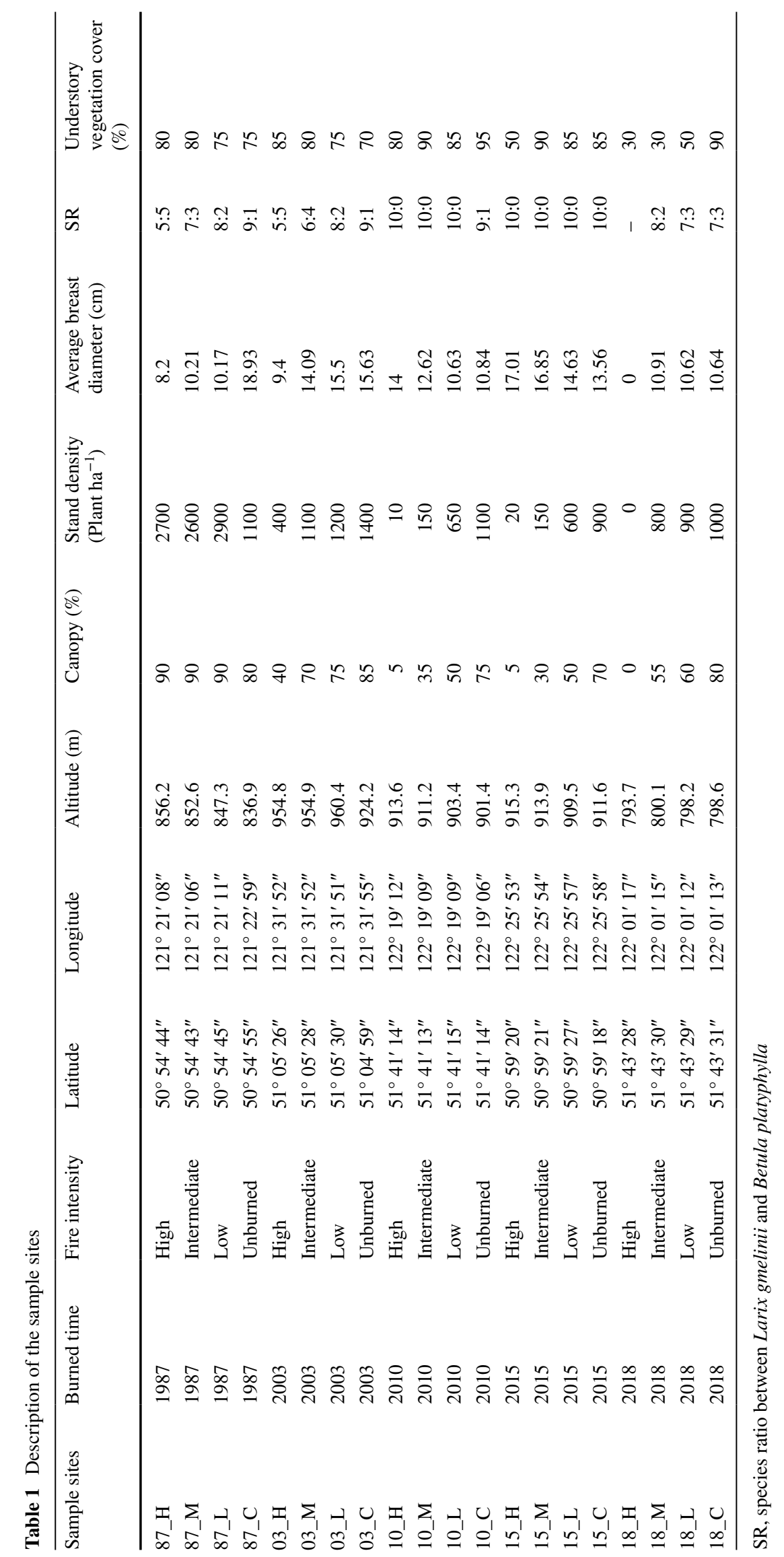


Table 2 Composite Burn Index survey content and evaluation criteria

\begin{tabular}{|c|c|c|c|c|c|}
\hline \multirow{2}{*}{$\begin{array}{l}\text { Vegetation } \\
\text { layer }\end{array}$} & \multirow[t]{2}{*}{ Fire characterization } & \multicolumn{4}{|c|}{ Forest burned intensity } \\
\hline & & Unburned 0 & Low 1 & Intermediate 2 & High 3 \\
\hline \multirow[t]{4}{*}{ A } & Litter consumption & No change & $50 \%$ Litter consumed & $100 \%$ Litter consumed & $\begin{array}{l}80 \% \text { Fine } \\
\text { combustibles } \\
\text { consumed }\end{array}$ \\
\hline & Humus consumption & No change & $20 \%$ consumed & $50 \%$ consumed & $100 \%$ consumed \\
\hline & Consumption of fallen wood & No change & $20 \%$ consumed & $40 \%$ consumed & $60 \%$ consumed \\
\hline & Soil thickness/coverage/color & No change & $10 \%$ changed & $40 \%$ changed & $80 \%$ changed \\
\hline \multirow[t]{3}{*}{ B } & Survival rate & $100 \%$ & $90 \%$ & $50 \%$ & $20 \%$ \\
\hline & Plant colonization & No change & Low & Intermediate & High \\
\hline & Species composition/diversity & No change & $20 \%$ changed & $40 \%$ changed & $60 \%$ changed \\
\hline \multirow[t]{3}{*}{$\mathrm{C}$} & Forest mortality & 0 & $15 \%$ & $60 \%$ & $>80 \%$ \\
\hline & Blackened height & - & $1.5 \mathrm{~m}$ & $2.8 \mathrm{~m}$ & $>5 \mathrm{~m}$ \\
\hline & Canopy mortality & 0 & $15 \%$ & $60 \%$ & $>80 \%$ \\
\hline \multirow[t]{3}{*}{ D } & Forest mortality & 0 & $10 \%$ & $50 \%$ & $>70 \%$ \\
\hline & Blackened height & - & $1.8 \mathrm{~m}$ & $4 \mathrm{~m}$ & $>7 \mathrm{~m}$ \\
\hline & Canopy mortality & 0 & $10 \%$ & $50 \%$ & $>70 \%$ \\
\hline
\end{tabular}

A, surface combustibles and soil layer; B, herbs, low shrubs and small tree layer with $<1 \mathrm{~m}$ height; $\mathrm{C}$, tall shrubs and tree layer 1-5 $\mathrm{m}$ height; $\mathrm{D}$, tree layer $>5 \mathrm{~m}$ height

Table 3 Forest burned intensity classification based on CBI with 2015 burned area as an example

\begin{tabular}{llllll}
\hline Forest burned intensity & $\begin{array}{l}\text { Number of } \\
\text { plots }\end{array}$ & Maximum & Minimum & Mean & Standard deviation \\
\hline Low & 20 & 1.1286 & 0.1178 & 0.8857 & 0.310691 \\
Intermediate & 18 & 1.9857 & 1.2714 & 1.7286 & 0.31499 \\
High & 22 & 2.7 & 1.5571 & 2.2259 & 0.322 \\
\hline
\end{tabular}

Daxing' anling. By calculating the CBI and grading the FSI of the burned areas created in different times, one low severity plot, one intermediate severity plot and one high severity plot were selected in each block. An unburned plot near the burned area was also selected which had the same site condition. There were 20 plots in total.

\section{Sample collection}

Three sampling points were randomly selected in each plot. With the sampling point as center, and within 3-m diameter, an auger with a $3-\mathrm{cm}$ inner diameter was used to collect 10 samples at $1-10 \mathrm{~cm}$ depths. The samples were mixed and screened through a $2 \mathrm{~mm}$-sieve, packed in self-sealing bags and stored at $-20^{\circ} \mathrm{C}$. These samples were used for measuring the chemical properties, bacterial diversity, and fungal diversity of the soil.

\section{Measurement of soil chemical properties}

An aqueous extract of potassium chloride solution was used to determine $\mathrm{pH}$ (measurement standard: NY/T 1377-2007); an potassium dichromate volumetric method to measure total organic carbon (TOC) (measurement standard: NY/T 1121.6-2006); the Kjeldahl distillation was used to measure total nitrogen (TN) (measurement standard: NY/T 53-1987); the sodium hydroxide fusion-molybdenum stibium resist colorimetric method was used to measure total phosphorus (TP) (measurement standard: NY/T 88-1988) and total potassium (TK) (measurement standard: NY/T 87-1988); the alkaline hydrolysis diffusion method was used to measure available nitrogen (AN) (measurement standard: DB13T 843-2007); and, the sodium bicarbonate extraction-molybdenum stibium resist colorimetric method was used to measure available phosphorus (AP) (measurement standard: NY/T 1121.7-2014) (Table 4).

\section{DNA extraction and PCR amplification}

Total DNA of the microbial communities were extracted according to the instructions of E.Z.N.A. ${ }^{\circledR}$ soil DNA kit (Omega Bio-tek, Norcross, GA, USA.). A 1\% agarose gel electrophoresis was applied to detect the DNA extraction quality while the NanoDrop2000 determined the DNA 
Table 4 Soil chemical properties

\begin{tabular}{|c|c|c|c|c|c|c|c|}
\hline Sample plots & $\mathrm{TN}\left(\mathrm{g} \mathrm{kg}^{-1}\right)$ & $\mathrm{TP}\left(\mathrm{g} \mathrm{kg}^{-1}\right)$ & $\mathrm{TK}\left(\mathrm{g} \mathrm{kg}^{-1}\right)$ & $\mathrm{AN}\left(\mathrm{mg} \mathrm{kg}^{-1}\right)$ & $\mathrm{AP}\left(\mathrm{mg} \mathrm{kg}^{-1}\right)$ & TOC $\left(\mathrm{g} \mathrm{kg}^{-1}\right)$ & $\mathrm{pH}$ \\
\hline 87_C & $6.4 \pm 1.1 \mathrm{a}$ & $0.5 \pm 0.01 \mathrm{a}$ & $16.5 \pm 0.8 \mathrm{a}$ & $110.9 \pm 22.2 \mathrm{a}$ & $29.6 \pm 4.4 \mathrm{a}$ & $79.6 \pm 11.9 a$ & $4.6 \pm 0.2 b$ \\
\hline 87_L & $6.3 \pm 1.5 \mathrm{a}$ & $0.5 \pm 0.01 \mathrm{a}$ & $16.8 \pm 0.7 \mathrm{a}$ & $103.4 \pm 16.5 \mathrm{a}$ & $26.8 \pm 1.3 b$ & $78.8 \pm 29.2 \mathrm{ab}$ & $5.0 \pm 0.2 b$ \\
\hline 87_M & $6.2 \pm 1.9 \mathrm{a}$ & $0.5 \pm 0.05 \mathrm{a}$ & $18.6 \pm 2.2 \mathrm{a}$ & $109.0 \pm 25.1 \mathrm{a}$ & $25.7 \pm 4.6 b$ & $70.5 \pm 20.5 \mathrm{ab}$ & $5.1 \pm 0.2 \mathrm{ab}$ \\
\hline 87_H & $5.6 \pm 2.2 b$ & $0.5 \pm 0.09 \mathrm{a}$ & $18.0 \pm 3.1 \mathrm{a}$ & $116.9 \pm 31.6 a$ & $14.8 \pm 7.6 \mathrm{c}$ & $67.2 \pm 24.9 b$ & $5.3 \pm 0.3 a$ \\
\hline 03_C & $2.5 \pm 0.5 \mathrm{a}$ & $0.2 \pm 0.01 \mathrm{a}$ & $25.0 \pm 0.8 \mathrm{~b}$ & $109.3 \pm 18.6 \mathrm{a}$ & $18.5 \pm 1.1 \mathrm{a}$ & $25.7 \pm 4.1 \mathrm{a}$ & $5.2 \pm 0.2 b$ \\
\hline 03_L & $2.7 \pm 0.6 \mathrm{a}$ & $0.2 \pm 0.0 \mathrm{a}$ & $25.9 \pm 1.3 \mathrm{a}$ & $111.5 \pm 23.4 \mathrm{a}$ & $19.1 \pm 1.5 \mathrm{a}$ & $26.7 \pm 7.2 \mathrm{a}$ & $5.3 \pm 0.1 b$ \\
\hline 03_M & $2.3 \pm 0.8 \mathrm{ab}$ & $0.2 \pm 0.02 \mathrm{a}$ & $25.7 \pm 5.4 \mathrm{a}$ & $115.0 \pm 33.3 \mathrm{a}$ & $13.1 \pm 2.5 b$ & $22.4 \pm 7.6 \mathrm{ab}$ & $5.4 \pm 0.2 \mathrm{ab}$ \\
\hline 03_H & $1.9 \pm 0.8 b$ & $0.2 \pm 0.02 b$ & $26.9 \pm 4.7 \mathrm{a}$ & $105.7 \pm 47.5 \mathrm{a}$ & $8.4 \pm 5.2 \mathrm{c}$ & $16.8 \pm 6.9 \mathrm{~b}$ & $5.7 \pm 0.4 \mathrm{a}$ \\
\hline 10_C & $4.2 \pm 0.9 \mathrm{a}$ & $0.4 \pm 0.01 b$ & $14.5 \pm 1.4 \mathrm{c}$ & $105.8 \pm 23.5 \mathrm{a}$ & $45.9 \pm 2.0 \mathrm{a}$ & $50.7 \pm 9.4 a$ & $4.3 \pm 0.2 b$ \\
\hline 10_L & $4.3 \pm 1.3 \mathrm{a}$ & $0.4 \pm 0.01 \mathrm{a}$ & $25.0 \pm 1.4 \mathrm{~b}$ & $87.2 \pm 19.3 b$ & $40.6 \pm 0.8 b$ & $52.8 \pm 8.3 \mathrm{a}$ & $4.4 \pm 0.1 b$ \\
\hline 10_M & $4.0 \pm 1.6 \mathrm{a}$ & $0.4 \pm 0.05 b$ & $22.9 \pm 4.7 b$ & $100.3 \pm 31.3 \mathrm{a}$ & $19.4 \pm 3.4 \mathrm{c}$ & $42.4 \pm 16.0 \mathrm{a}$ & $4.7 \pm 0.2 \mathrm{ab}$ \\
\hline 10_H & $2.3 \pm 1.1 b$ & $0.4 \pm 0.05 b$ & $29.3 \pm 3.4 \mathrm{a}$ & $107.2 \pm 34.1 \mathrm{a}$ & $10.4 \pm 5.8 \mathrm{~d}$ & $17.0 \pm 10.7 b$ & $4.9 \pm 0.3 \mathrm{a}$ \\
\hline 15_C & $5.6 \pm 0.9 a$ & $0.5 \pm 0.01 b$ & $26.9 \pm 0.8 b$ & $91.3 \pm 16.4 b$ & $19.1 \pm 2.5 \mathrm{a}$ & $67.7 \pm 8.8 \mathrm{a}$ & $4.2 \pm 0.2 \mathrm{c}$ \\
\hline 15_L & $5.7 \pm 1.1 \mathrm{ab}$ & $0.6 \pm 0.02 \mathrm{a}$ & $24.4 \pm 0.5 \mathrm{c}$ & $87.1 \pm 12.2 b$ & $13.5 \pm 0.6 b$ & $69.3 \pm 15.0 \mathrm{a}$ & $4.8 \pm 0.2 b$ \\
\hline 15_M & $4.1 \pm 1.3 b$ & $0.7 \pm 0.05 \mathrm{a}$ & $27.3 \pm 3.0 \mathrm{a}$ & $105.1 \pm 22.1 \mathrm{ab}$ & $20.9 \pm 1.9 \mathrm{a}$ & $55.8 \pm 11.9 b$ & $4.9 \pm 0.2 \mathrm{a}$ \\
\hline 15_H & $1.3 \pm 0.5 \mathrm{c}$ & $0.6 \pm 0.04 \mathrm{a}$ & $27.2 \pm 2.6 \mathrm{a}$ & $112.7 \pm 28.2 \mathrm{a}$ & $12.1 \pm 4.6 b$ & $13.6 \pm 4.8 \mathrm{c}$ & $5.0 \pm 0.3 \mathrm{a}$ \\
\hline 18_C & $2.3 \pm 0.5 \mathrm{a}$ & $0.5 \pm 0.03 \mathrm{c}$ & $16.7 \pm 0.8 \mathrm{c}$ & $84.4 \pm 16.0 \mathrm{bc}$ & $46.9 \pm 4.6 b$ & $23.3 \pm 4.2 \mathrm{a}$ & $5.2 \pm 0.3 b$ \\
\hline 18_L & $2.3 \pm 0.5 \mathrm{ab}$ & $0.5 \pm 0.02 b$ & $16.9 \pm 1.2 \mathrm{c}$ & $84.2 \pm 16.4 \mathrm{c}$ & $55.1 \pm 4.2 \mathrm{a}$ & $31.3 \pm 6.7 \mathrm{a}$ & $5.2 \pm 0.2 b$ \\
\hline 18_M & $1.7 \pm 0.5 b$ & $0.5 \pm 0.05 b$ & $20.5 \pm 2.4 b$ & $87.2 \pm 27.0 \mathrm{~b}$ & $54.4 \pm 8.3 \mathrm{a}$ & $19.0 \pm 6.9 b$ & $5.3 \pm 0.3 \mathrm{a}$ \\
\hline 18_H & $1.1 \pm 0.5 \mathrm{c}$ & $0.6 \pm 0.05 a$ & $24.7 \pm 3.1 \mathrm{a}$ & $112.7 \pm 31.6 \mathrm{a}$ & $41.6 \pm 15.2 \mathrm{c}$ & $11.4 \pm 4.9 \mathrm{c}$ & $5.6 \pm 0.4 \mathrm{a}$ \\
\hline
\end{tabular}

Value is the mean \pm standard deviation; different letters in the same column represent the significant difference between different fire intensity plots in the same time series $(p<0.05)$

concentration and purity. For bacterial samples, the $338 \mathrm{~F}$ (5'-ACTCCTACGGGAGGCAGCAG-3') and 806R (5'GGACTACHVGGGTWTCTAAT- 3 ') were used to carry out PCR amplification for the V3-V4 variable region of 16S rRNA gene; for fungal samples, ITS 1 (5'-TCCGTA GGTGAACCTGCGG-3') and ITS4 (5'-TCCTCCGCTTAT TGATATGC-3') were applied to perform PCR amplification for the ITS region of rRNA gene. Each operation was repeated three times on each sample.

\section{High-throughput sequencing}

The PCR products of the same sample were mixed and recycled using $2 \%$ agarose gel, and then purified the recycled products by AxyPrep DNA Gel Extraction Kit (Axygen Biosciences, Ltd, Union City, CA, USA). A 2\% agarose gel electrophoresis was carried out and the recycled products quantified by Quantus ${ }^{\mathrm{TM}}$ Fluorometer (Promega, Ltd, Madison City, WI, USA). NEXTFLEX Rapid DNASeq Kit was next applied to set up a library and sequencing was performed by Miseq PE300 platform (Illumina, Ltd, San Diego City, CA, USA) of the company. The original data were uploaded to the NCBI SRA (Sequence Read Archive) database.

\section{Biological information extraction}

Trimmomatic software (version 0.39, http://www.usadellab. $\mathrm{org} / \mathrm{cms} /$ ?page=trimmomatic) was applied to control the quality of original sequencing, and the FLASH software used for splicing. UPARSE software (version 7.1, http:// drive5.com/uparse/) was used to carry out OTU clustering and to eliminate chimera on sequence according to $97 \%$ similarity. The RDP classifier (http://rdp.cme.msu.edu/) was then used to carry out species classification and annotation for each sequence, and the bacterial and fungal samples were compared with Silva database (Release132, http://www.arbsilva.de) and Unite database (Release 7.2, http://unite.ut.ee/ index.php), respectively, for which the comparison threshold was set as $70 \%$.

\section{Data processing}

SPSS (IBM, USA) software was used to calculate the mean and standard deviation of each chemical factor and to perform significance analysis. The mothur software package was used to calculate the diversity index and the R programming language (AT\&T Bell Laboratories, Ltd, Hurray Hill City, NJ, USA) vegan package to carry out redundancy analysis (RDA) and canonical correspondence analysis (CCA) 
by taking the soil microbial OTU horizontal community composition as the response variable. Soil chemical characteristics were set as the explanatory variable. PICRUSt2 software (https://github.com/picrust/picrust2/wiki) predicted the functions of soil bacteria and fungi, screened the key functional enzymes in the soil carbon, nitrogen, and phosphorus cycles. Excel 2019 and R Studio software were used to process the data and Origin 2018 (Origin Laboratories, Ltd, Northampton City, MA, USA) software for drawing.

\section{Results}

\section{Chemical properties of soils}

The mixed forest soil of Daxing'anling has $\mathrm{pH}$ 4.5-5.2 with total organic carbon (TOC) content of $23.2-80.6 \mathrm{~g} \mathrm{~kg}^{-1}$, total nitrogen (TN) of 2.2-6.9 $\mathrm{g} \mathrm{kg}^{-1}$, and total phosphorus (TP) of $0.2-0.5 \mathrm{~g} \mathrm{~kg}^{-1}$ (Table 4).

Eight weeks after fire in soils subjected to intermediate/high severity burning, the TOC, TN, and AP contents dropped significantly, but soil $\mathrm{pH}$ rose dramatically. TP, TK, and AN levels increased slightly. In soil under a low severity fire, $\mathrm{pH}$ rose slightly and TOC, TN, TP, TK, AN, and AP levels increased slightly. Fifteen years after the fire, TP, $\mathrm{TK}$, and AN contents were restored to pre-fire levels. Thirty years after fire, TOC and TN contents as well as $\mathrm{pH}$ were at pre-fire levels. Over time, the AP content gap between the burned area and the control plot increased significantly (Table 4).

\section{Soil bacterial community characteristics}

\section{Structural characteristics}

The 16SrRNA high-throughput sequencing was carried out on all 60 soil samples of 20 groups. There were 3,302,646 high quality sequences with 432 bp mean reading length obtained after quality control and chimera removed, and were clustered into 4771 OTUs ( $97 \%$ similarity), belonging to 33 phylum, 234 orders, and 604 genera.

The predominant bacterial phylum, (relative abundance ratio in each sample above $0.1 \%$ ) in unburned soils include: Acidobacteria $(28.2 \% \pm 3.8 \%)$, Proteobacteria $(25.1 \% \pm 4.0 \%)$, Actinobacteria $(16.5 \% \pm 1.6 \%)$, Chloroflexi $(10.0 \% \pm 4.5 \%)$, Verrucomicrobia $(3.3 \% \pm 2.2 \%)$, Planctomycetes $(3.0 \% \pm 1.7 \%)$, Gemmatimonadetes $(2.6 \% \pm 1.8 \%)$, Bacteroidetes $(2.1 \% \pm 1.6 \%)$, Cyanobacteria $(0.2 \% \pm 0.1 \%)$, Firmicutes $(0.4 \% \pm 0.2 \%)$, and Nitrospirae $(0.2 \% \pm 0.3 \%)$. The total relative abundance ratio is over $95 \%$ (Fig. 1, Fig. S2).

Fire results in significant changes in bacterial community structure. In soils under high severity fire, the relative

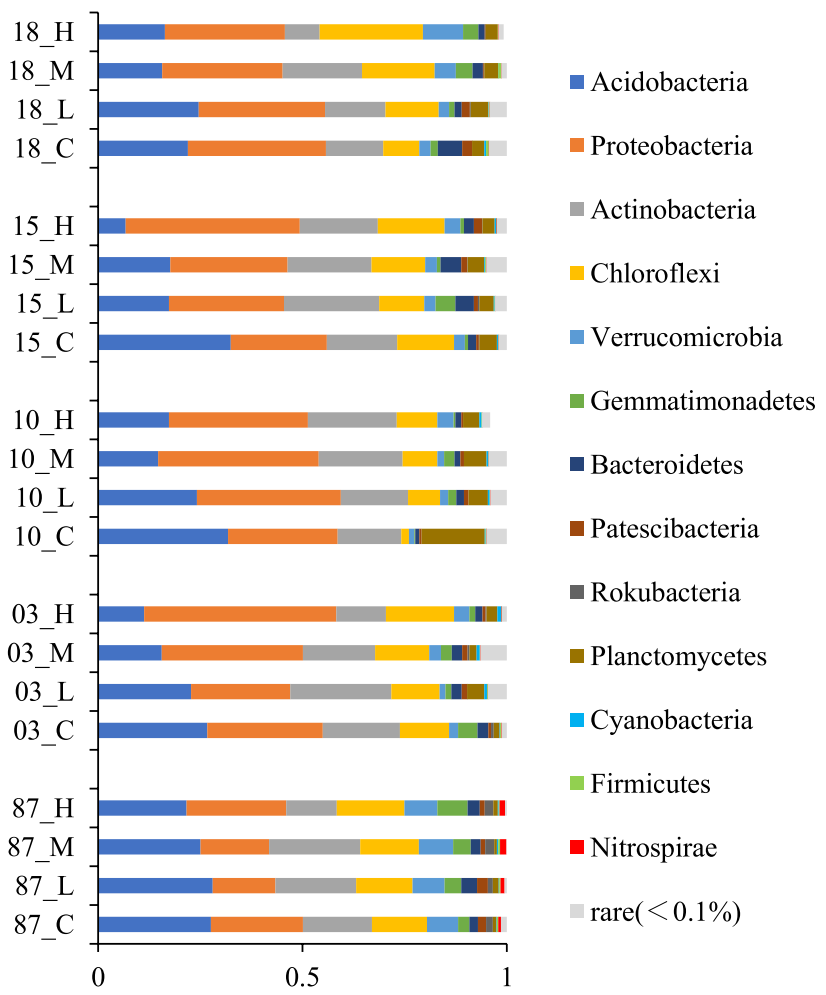

Fig. 1 Soil bacterial community composition at the phylum level

abundance ratios of a portion of the dominant soil bacteria decreased dramatically, including: Acidobacteria $(14.7 \% \pm 5.2 \%)$, Actinobacteria $(14.8 \% \pm 0.5 \%)$, Planctomycetes $(2.8 \% \pm 0.9 \%)$ and Firmicutes $(0.1 \% \pm 0.1 \%)$, while other parts increased significantly; Proteobacteria $(35.5 \% \pm 8.3 \%)$, Chloroflexi $(16.9 \% \pm 4.9 \%)$, Verrucomicrobia $(5.9 \% \pm 2.6 \%)$, Cyanobacteria $(0.6 \% \pm 0.2 \%)$, and Nitrospirae $(0.3 \% \pm 0.1 \%)$. With an increase of recovery time, the changes to the bacterial community structure gradually decreased. Thirty years after the fire, it was essentially restored to pre-fire levels. In soils with low/intermediate severity fire, the relative abundance ratios of Actinobacteria $(20.0 \% \pm 2.9 \%)$ and Planctomycetes $(3.4 \% \pm 1.5 \%)$ increased significantly. With an increase in recovery time, the bacterial community structure gradually recovered and was restored to pre-fire levels. The changes by other bacterial phylum were similar to those of bacteria under high severity fire.

\section{Bacterial diversity characteristics}

Chao and Shannon indexes, respectively, characterize the abundance ratio and diversity of bacterial species (Fig. 2). Eight weeks after the fire, both the richness index and diversity indexes were reduced dramatically; 3 years after the fire, the two indexes increased beyond pre-fire levels; 15 years later, the two indexes dropped to pre-fire levels. The $\beta$ diversity characteristics of soil bacteria in all plots is shown by 

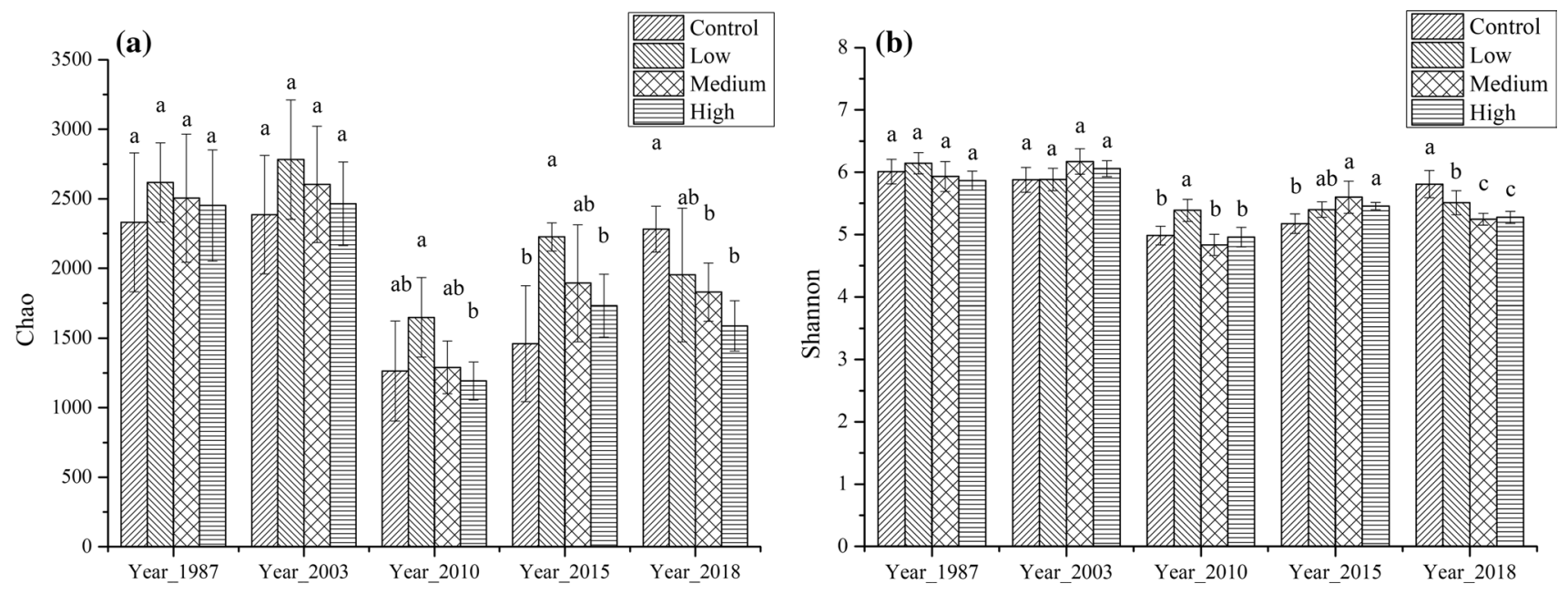

Fig. 2 Soil bacterial $\alpha$ diversity characteristics: a Chao indexes; b Shannon indexes

RDA analysis. All plots are located in five agglomeration areas which take the sampling site as the center (Fig. 3). Soil bacteria are capable of resisting disturbance and able to maintain a relatively stable community structure and restore rapidly after fire.

\section{Influence of environmental factors on bacterial communities}

From the redundancy analysis (RDA) (Fig. 3), it is clear that the explained variable in the first and second axes are $17.7 \%$ and $7.7 \%$, respectively, and the cumulative contribution rate is $25.45 \%(p<0.01)$. Soil $\mathrm{pH}$, TOC, and AP are explained by $19.31 \%, 18.21 \%$, and $17.69 \%$ of the variance, respectively.

(a)

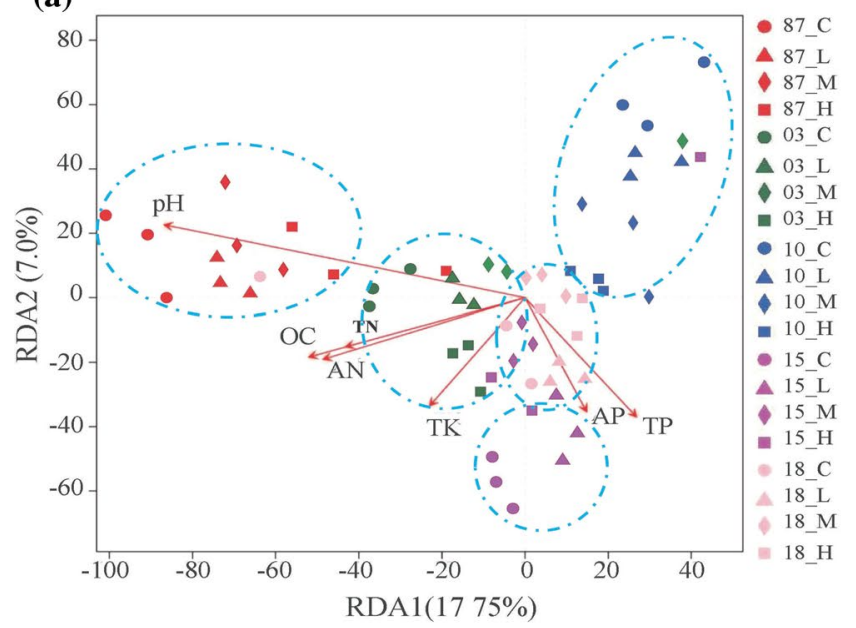

The cover vegetation has less effect on soil bacterial community (Fig. 3); the explained variable in the first and second axes are $17.75 \%$ and $7.7 \%$, respectively, and the cumulative contribution rate is $25.45 \%(p<0.01)$.

\section{Characteristics of soil fungal community}

\section{Structural characteristics}

The ITS rRNA high-throughput sequencing was carried out on all 60 soil samples of 20 groups. There were 3,302,646 high quality sequences with $432 \mathrm{bp}$ mean reading length obtained after quality control and chimera removal, which were clustered into 4771 OTUs ( $97 \%$ similarity), belonging to 33 phylum, 234 orders, and 604 genera.

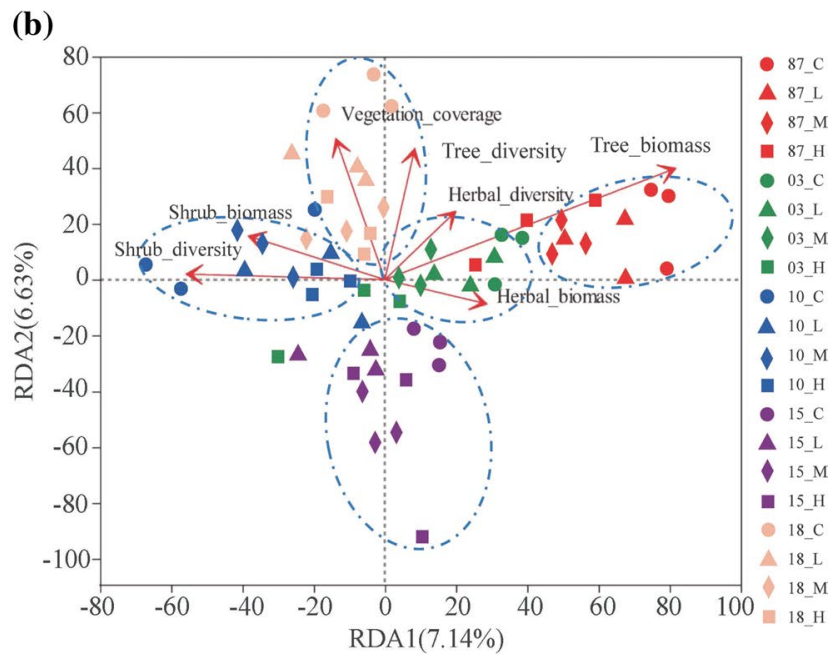

Fig. 3 Results of RDA analysis of bacteria: a redundancy analysis (RDA) of bacterial community structure and soil chemical properties; $\mathbf{b}$ RDA of bacterial community structure and vegetation factor redundancy analysis 
The predominant fungal orders, (relative abundance ratio in each sample is above $0.3 \%$ ), in unburned soils were Helotiales $(36.7 \% \pm 18.0 \%)$, Thelebolales $(3.4 \% \pm 3.3 \%)$, Eurotiales $(0.7 \% \pm 0.9 \%)$, Hypocreales $(0.3 \% \pm 0.2 \%)$, Archaeorhizomycetales $(0.2 \% \pm 0.2 \%)$ of Ascomycota phylum; Agaricales $(15.6 \% \pm 13.0 \%)$, Russulales $(10.6 \% \pm 6.5 \%)$, Thelephorales $(8.8 \% \pm 8.0 \%)$, and Atheliales $(1.2 \% \pm 1.4 \%)$ of Basidiomycota phylum; and Mortierellales $(3.4 \% \pm 2.6 \%)$ of Mortierellomycota phylum. The total relative abundance ratio was over $70 \%$ (Fig. 4).

Fire causes significant changes in the soil fungal community structure. In soil under high severity fire, the relative abundance ratios of Archaeorhizomycetales $(38.1 \% \pm 19.4 \%)$, Eurotiales $(5.8 \% \pm 6.4 \%)$, and Hypocreales $(0.8 \% \pm 0.9 \%)$ were significantly increased, while that of Helotiales $(19.0 \% \pm 14.4 \%)$, Thelebolales $(1.6 \% \pm 1.1 \%)$, Agaricales $(1.4 \% \pm 1.4 \%)$, Atheliales $(0.1 \% \pm 0.1 \%)$, Russulales $(2.3 \% \pm 3.7 \%)$, and Thelephorales $(1.5 \% \pm 1.5 \%)$ were significantly reduced. With an increase of recovery time, changes to community structure gradually decreased. Thirty years post-fire, the community structure had not been restored to pre-fire levels. In soils under low/intermediate severity fire, the relative abundance ratios of Archaeorhizomycetales $(6.1 \% \pm 12.1 \%)$ and Eurotiales $(2.2 \% \pm 5.5 \%)$ increased significantly while that of Agaricales (5.9\% $\pm 5.8 \%)$ and Russulales $(6.8 \% \pm 6.5 \%)$ were significantly reduced; there was no change for Helotiales $(38.8 \% \pm 20.3 \%)$. With an longer recovery time, the bacterial community structure gradually recovered to prefire levels after 30 years (Fig. 4).

\section{Fungal diversity characteristics}

The soil fungal diversity index (value range: $1.5-3.5$ ) was significantly lower than the soil bacterial diversity index (value range: 5.0-6.5) (Fig. 5). After fire, fungal richness and diversity indexes were dramatically reduced. With increased recovery time, abundance ratios and diversity index gradually recovered; the abundance ratio was restored to pre-fire levels after 30 years while the diversity index did not (Fig. 5).

From the $\beta$ diversity characteristics of soil fungi, it is apparent that: the high severity burned and the low/intermediate severity burned areas have fungi in two clusters (Fig. 6). Fungi are more sensitive to environmental changes than bacteria after fire. This is because soil fungi have a homogeneous structure and are mainly distributed over a few predominant phyla. They are unstable and have poor adaptability to disturbance, and easily show significant changes in community structure after fire, requiring a length period for restoration.

\section{Influences of environmental factors on fungal communities}

The results of the canonical correspondence analysis (CCA) (Fig. 6) show that soil factors have little influence on the fungal community. The relative explained variable in the first and second axes are $7.1 \%$ and $6.4 \%$, respectively. The cumulative contribution rate is $13.6 \%(p<0.01)$. Soil $\mathrm{pH}$, TOC and AP contents explain $9.0 \%, 8.9 \%$ and $6.7 \%$ variance, respectively, which indicates that these are the main factors affecting soil fungal communities.
Fig. 4 Soil fungal community composition at the order level

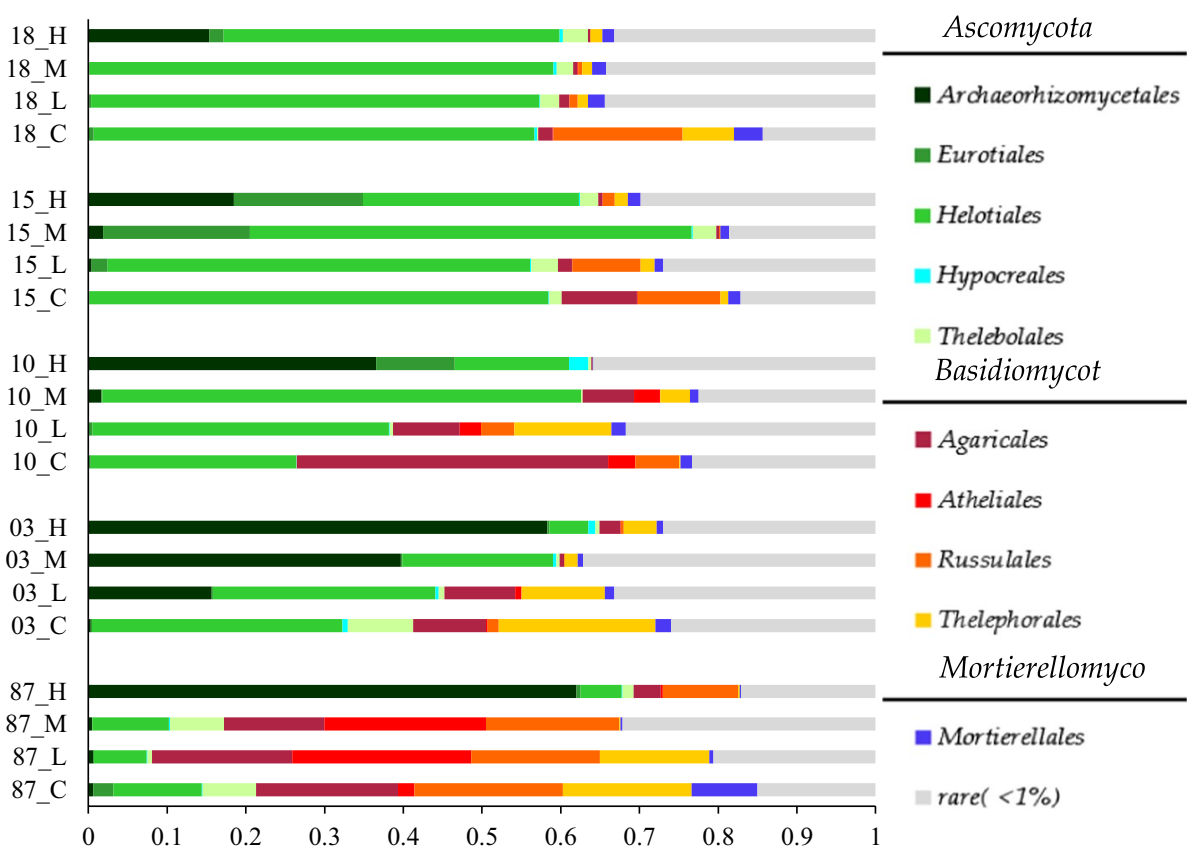



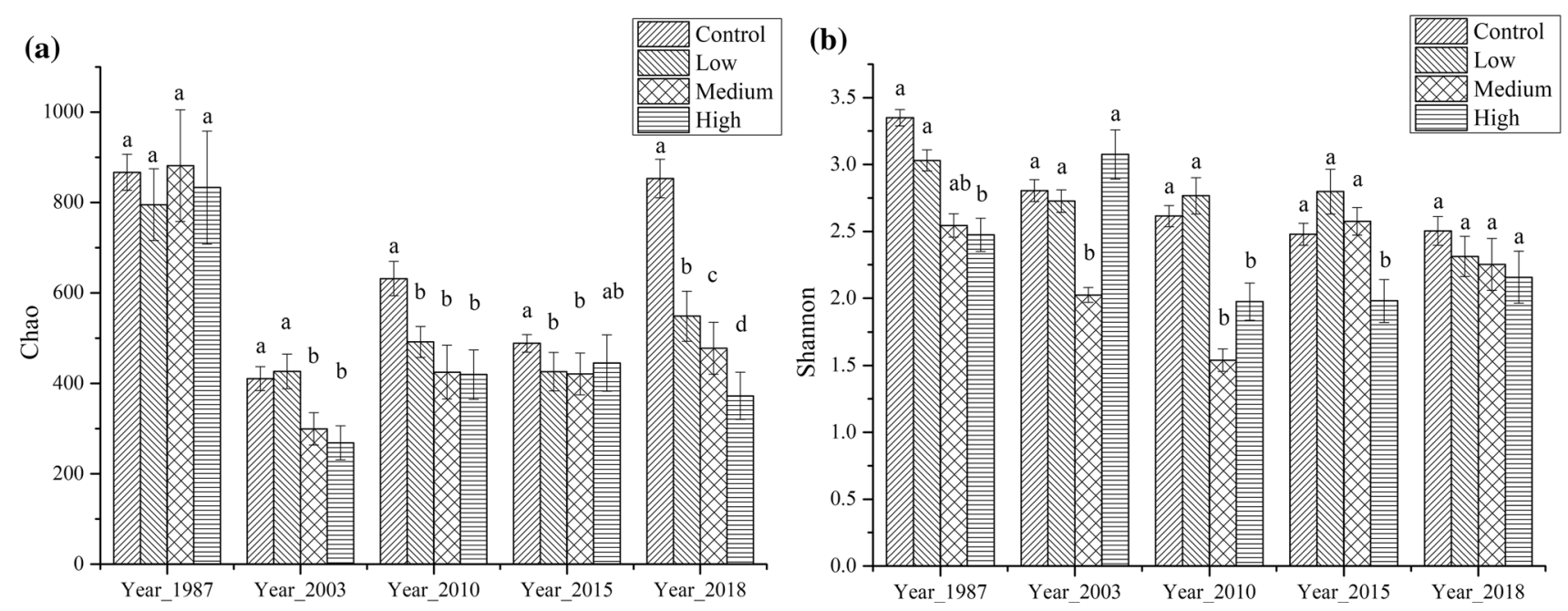

Fig. 5 Soil fungal $\alpha$ diversity characteristics: a Chao indexes; b Shannon indexes

(a)

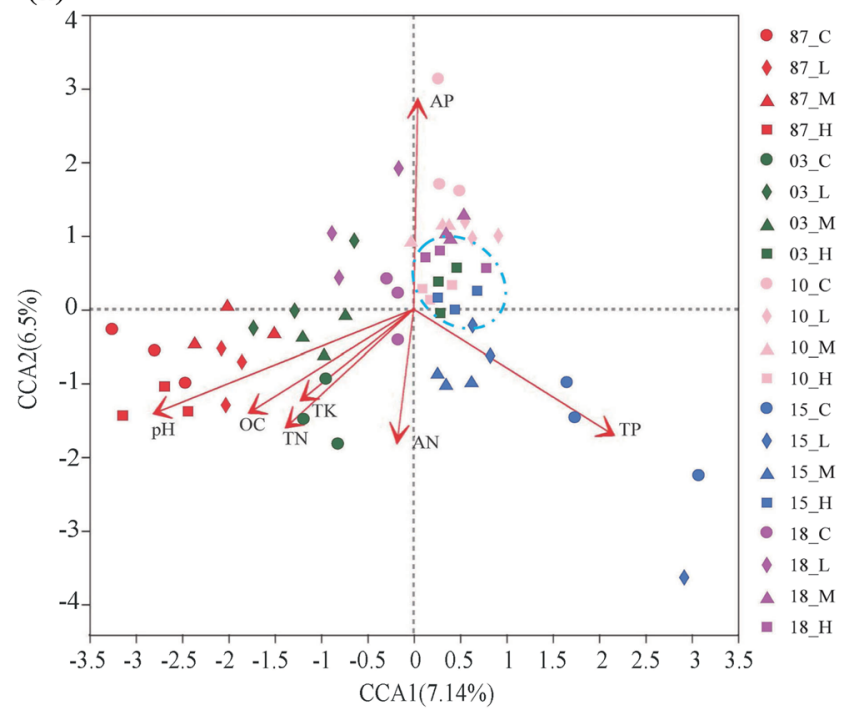

(b)

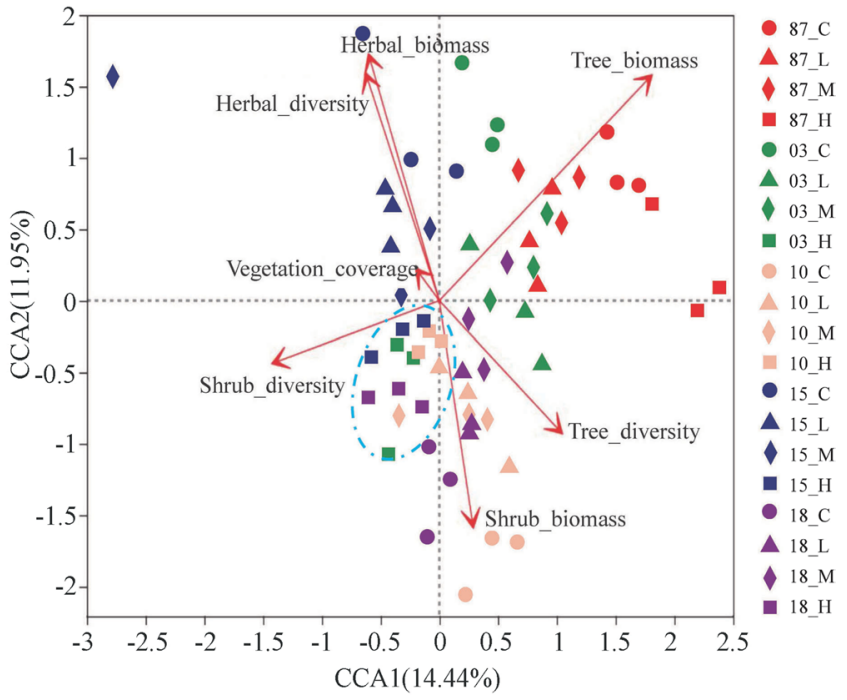

Fig. 6 Results of RDA analysis of fungi: a canonical correspondence analysis (CCA) of fungal community structure and chemical properties; b $\mathrm{CCA}$ of fungal community structure and vegetation factor redundancy analysis

The vegetation factors such as tree biomass, herbaceous biomass, and herbaceous diversity can greatly affect the fungal community. The explained variable in the first and second axes are $14.4 \%$ and $11.9 \%$, respectively. The cumulative contribution rate is $26.4 \%(p<0.01)$. Tree biomass, herbaceous biomass, and herbaceous diversity respectively explain $18.7 \%, 16.0 \%$, and $15.6 \%$ variance, respectively, showing that they are the main influencing factors on soil fungal communities (Fig. 6).

\section{Prediction on soil functions}

PICRUSt2 was applied to identify the functional characteristics of soil microbes related to element cycling. Among the functions that the soil bacteria are involved in, the dominating genes were those relating to the anaerobic acetyl-CoA pathway and the 3-hydroxypropionic acid pathway in carbon fixation, and those involved in cellulose degradation, and organic phosphorus hydrolysis. Relative 
abundances of other functions were comparatively low. The analysis on carbon cycling functions showed that: after fire, with increasing severity, Calvin fixation was enhanced to an ever-increasing extent. Among them, the relative abundance ratios (relative abundance ratio refers to the ratio of the abundance of the soil enzyme to the sum of the abundance of all enzymes in the soil) of 1,5-ribulose bisphosphate carboxylase [EC: 4.1.1.39] ([EC:] represents the ID of each enzyme in the KEGG database.) involved in the Calvin cycle, carbon-monoxide dehydrogenase [EC:1.2.7.4] involved in anaerobic acetyl-CoA pathway, acetyl CoA carboxylase [EC:6.4.1.2] and propionyl-CoA carboxylase [EC:6.4.1.3] involved in 3-hydroxypropionate pathway were increasingly enhanced. The relative abundance ratios of 4-hydroxybutyryl-CoA dehydratase [EC: 4.2.1.120] involved in succinyl-CoA pathway, and the pyruvate carboxylase [EC:6.4.1.1] involved in oxaloacetate pathway were increasingly weakened. After increasing fire severity, cellulose and hemicellulose degradation were further enhanced. The relative abundance ratios of endoglucanase [EC:3.2.1.4], endo 1,3(4) beta glucanase [EC:3.2.1.6] and beta glucuronidase [EC:3.2.1.31] involved in cellulose degradation were increasingly weakened. The relative abundance ratios of xylan 1,4-betaxylosidase [EC:3.2.1.37] and endo-1,4-beta-xylanase involved in hemicellulose degradation were also weakened. After increasing fire severity, the relative abundance of catechol 1,2-dioxygenase [EC:1.13.11.1] involved in lignin degradation was enhanced. The analysis on nitrogen cycling showed that after fire, with increasing severity, the relative abundance ratio of a rate-limiting, enzyme-ammonia monooxygenase [EC: 1.14 .99 .39$]$ involved in nitrification was enhanced in ever increasing amounts, while the key enzymes involved in nitrogen fixation-nitrogenase iron protein NifH [EC:1.18.6.1] and nitrite reductase (NO-forming) [EC: 1.7.2.1] involved in denitrification were increasingly weakened. Phosphorus cycling analysis showed that with an increase in fire severity, the relative abundance ratios of alkaline phosphatase [EC: 3.1.3.1] and trehalose 6 phosphate hydrolase [EC: 3.2.1.93] were enhanced, while acid phosphatase [EC: 3.1 .3 .2$]$ weakened (Fig. 7).

Among the processes that soil fungi are involved in, the dominating genes are those relating to the oxaloacetate pathway and organic phosphorus hydrolysis in carbon fixation, while other functions were comparatively low abundances. The analysis of carbon cycling showed that with increasing fire severity, the relative abundance ratios of pyruvate carboxylase [EC:6.4.1.1], beta glucuronidase [EC:3.2.1.31] involved in cellulose degradation, and xylan 1,4-betaxylosidase [EC:3.2.1.37] involved in hemicellulose degradation were gradually weakened. Catechol 1,2-dioxygenase enzymes [EC:1.13.11.1] involved in lignin degradation were increasingly enhanced. The analysis of phosphorus cycling showed that after increasing fire severity, the relative abundance ratios of alkaline phosphatase [EC: 3.1.3.1] were enhanced while acid phosphatase [EC: 3.1 .3 .2$]$ was depleted (Fig. 8).

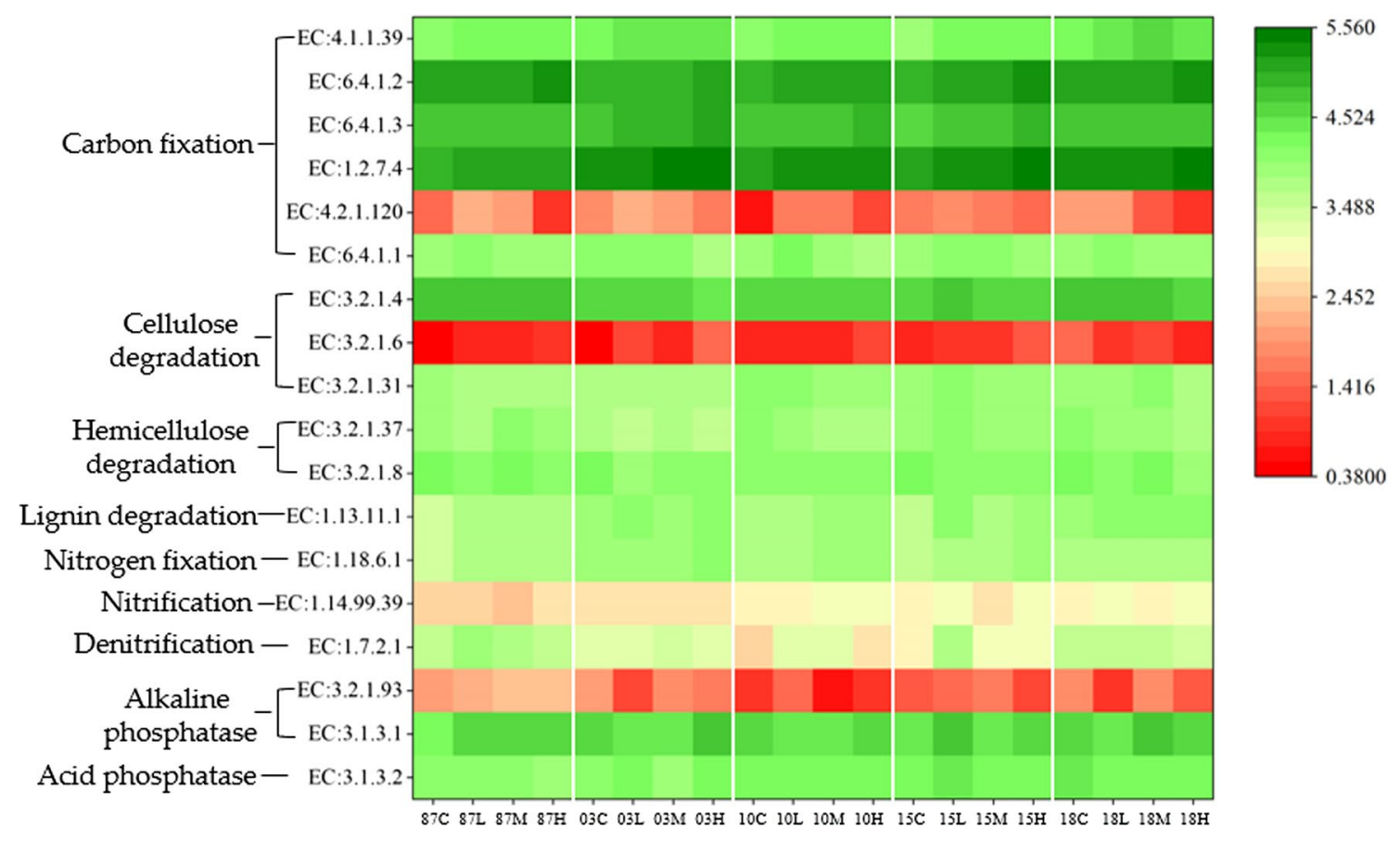

Fig. 7 PICRUSt2 function prediction results of soil bacterium 


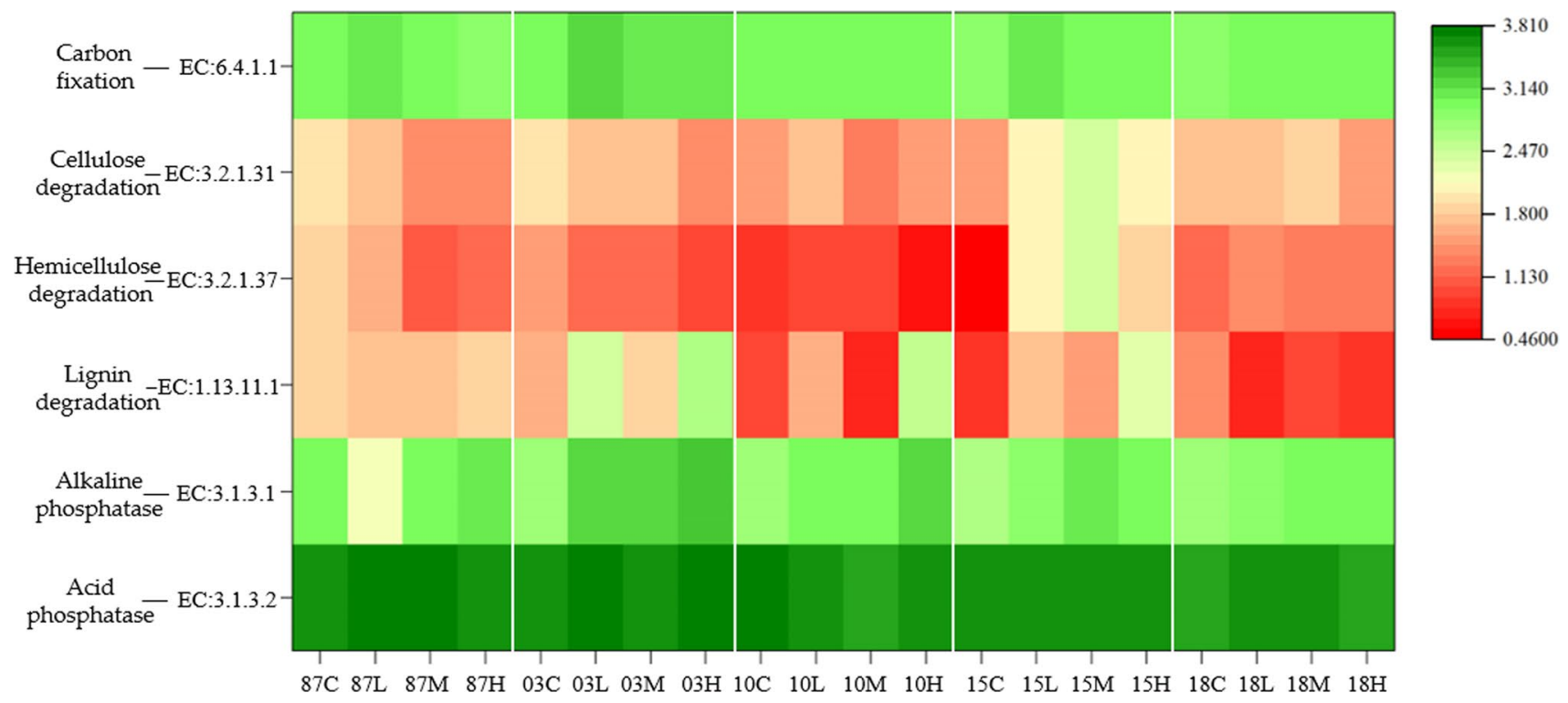

Fig. 8 PICRUSt2 function prediction results of soil fungi

\section{Discussion}

\section{Characteristics and driving factors of soil bacterial community structure after fire}

The soils of the Daxing' anling mixed forest contained similar bacterial communities, dominated by Acidobacteria, Proteobacteria, and Actinobacteria. After high severity fire disturbance, the two bacterial indexes of abundance ratio and diversity both declined dramatically. The structure also changed considerably to a community dominated by Proteobacteria and Chloroflexi. Over time, the indexes of abundance and diversity increased significantly to pre-fire levels 30 years after the fire. After low/intermediate-severity fire, Acidobacteria decreased significantly, while other bacteria increased slightly. Over time, the bacterial community which was originally dominated as noted above, was dominated by Proteobacteria, Actinobacteria and Chloroflexi. Mild fire disturbance only resulted in small changes to the soil bacteria.

When the environment changes, different bacteria show different coping strategies (k-strategy, r-strategy) due to their different survival characteristics. Acidobacteria, Actinobacteria, and Firmicutes are gram-positive bacteria (Fierer et al. 2007), which follow a "k-strategy (Kapazitätsgrenzestrategistis)" for survival, and were characterized by good growth in a stable environment but with a weak capability in adapting to a changed environment (Mickan et al. 2017); Proteobacteria, Gemmatimonadetes, and most Chloroflexi gram-negative bacteria (Chaudhry et al. 2012) with "r-strategy (rate-strategistis)" for survival, which features rapid growth and capable of adapting to new environment
(Mickan et al. 2017). Fontaine et al. (2003) considered that fast-growing "r-strategy" species dominated in the early stages of environmental change, and later, these species were replaced by "k-strategy" species when easy-to-degrade components of nutrition were depleted. In the study area, the soil environment was relatively stable. The "k-strategy" species like Acidobacteria and Actinobacteria dominated the soil bacteria communities. After fire disturbance, nutrition from organic matter were greatly reduced (Table 4), and the bacteria species changed. In this event, "r-strategy" species such as Proteobacteria and Chloroflexi, multiplied and became dominant. Then, when the soil environment tended to be stable again, "k-strategy" species gradually resumed a dominating status.

Among the environmental factors, vegetation has little effect on soil bacteria; $\mathrm{pH}$, TOC (total organic carbon) and AP (available phosphorous) have obvious effects. Soil $\mathrm{pH}$ was negatively correlated with the relative abundance of Acidobacteriales of the Acidobacteria phylum, Actinobacteria and Corynebacteriales of the Actinobacteria phylum, and Gemmatales and Isosphaerales of the Planctomycetes phylum It was positively correlated with Gaiellales and IMCC26256 of the Actinobacteria phylum, Betaproteobacteriales, Elsterales, Myxococcales and Rhizobiales of the Proteobacteria phylum, AD3 and KD4-96 of the Chloroflexi phylum, Chloroplast of the Cyanophyta phylum, Nitrospira of the Nitrospirae phylum, Chitinophagales of the Bacteroidetes phylum, and Chthoniobacterales of the Verrucobacteria phylum (Fig. 9). Austin and Smith (1990) found that $\mathrm{pH}$ had a direct physiological gradient on organisms, i.e., the growth of organisms is subject to the restraining level of $\mathrm{pH}$. The ability of different organisms to adapt to low $\mathrm{pH}$ is an 
Fig. 9 Correlation coefficients of soil bacterial community and environmental factors (**represents a significant difference between the factors at the 0.01 level; *a significant difference at the 0.05 level)

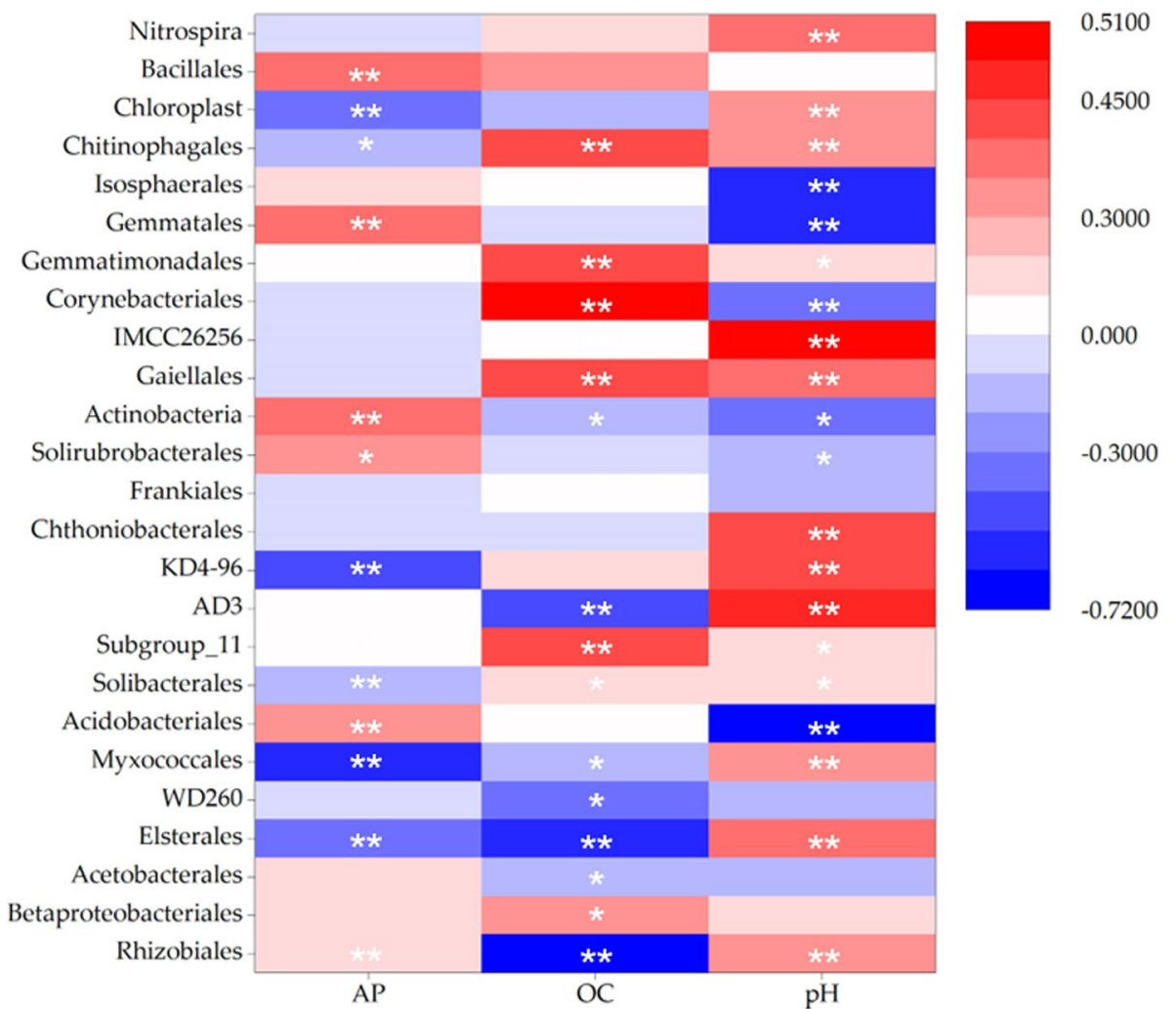

acid tolerance response (ATR). The optimal $\mathrm{pH}$ for Acidobacteria growth is $4-5$, having high ATR, but most bacteria grow better at a $\mathrm{pH} 7-8$ environment, having comparatively low acid tolerance. Soil $\mathrm{pH}$ in the study area was 4.2-5.2 so that, compared to other bacteria, Acidobacteriales and other bacteria of the same kind, which possessed higher ATR, were more competitive. But due to the alkaline hydrolysis effect of ash contents after fire, $\mathrm{pH}$ rose slightly to 4.6-5.6. At this $\mathrm{pH}$, the competitiveness of Acidobacteria was weakened while the relative abundance of other bacteria increased accordingly.

Soil TOC (total organic carbon) was positively correlated with the relative abundance of Subgroup_11 of the Acidobacteria phylum, Gaiellales and Corynebacteriales of the Actinobacteria phylum, and Bacillales of the Firmicutes phylum (Fig. 9). Soil TOC is the main carbon source for heterotrophic microorganisms such as Acidobacteria, Actinobacteria, and Firmicutes. After fire, the loss of soil TOC showed significant depressing effects on these bacteria.

Available soil phosphorous was positively correlated with the relative abundance ratios of Acidobacteriales of the Acidobacteria phylum, Solirubrobacterales and Actinobacteria of the Actinobacteria phylum, Bacillales of the Firmicutes phylum, and Gemmatales of the Planctomycetes phylum, but negatively correlated to KD4-96 of the Chloroflexi phylum, Chloroplast of the Cyanobacteria phylum, and Elsterales and Myxococcales of the Proteobacteria phylum
(Fig. 9). Phosphorus is an important element of biological cells. Available soil phosphorous is directly absorbed and utilized by soil microorganisms, so that its level in the soil has an important influence on the growth of microorganisms. Total phosphorus $\left(0.21-0.49 \mathrm{~g} \mathrm{~kg}^{-1}\right)$ is lower than the total phosphorous $\left(0.41-1.5 \mathrm{~g} \mathrm{~kg}^{-1}\right)$ of the upper $10-\mathrm{cm}$ layer in generally all Chinese forest soils (Gholz et al. 2000; Mcgroddy et al. 2004; Han et al. 2005; Parton et al. 2007; Li et al. 2018) which confirms that soils of the study area lack phosphorus. In the meantime, after fire disturbance and due to appropriate environmental conditions, bacteria such as Chloroflexi, Cyanobacteria, and Proteobacteria multiplied and consumed any available phosphorous and allowed for the production of weak bacteria like Acidobacteria and Actinobacteria (Parton et al. 2007).

According to previous studies, total soil nitrogen and available nitrogen are strongly correlated to Planctomycetes, Firmicuates, and Proteobacteria bacteria (Mao and Qi 2015). However, the results of this study show that the levels of total and available nitrogen had little influence on bacteria, which is different from previous research findings. Total soil nitrogen (2.24-6.93 $\left.\mathrm{g} \mathrm{kg}^{-1}\right)$ in the study area is relatively higher than the total nitrogen levels $\left(1.2-6.35 \mathrm{~g} \mathrm{~kg}^{-1}\right)$ of the upper $10 \mathrm{~cm}$ layer in Chinese forests (Gholz et al. 2000; Mcgroddy et al. 2004; Han et al. 2005; Parton et al. 2007; Li et al. 2018), which indicates that the soils of the study area are not lacking in nitrogen; after the fire, however, total soil 
nitrogen decreased, the available nitrogen which is directly absorbed by organisms increased. Therefore, the level of nitrogen resources was not restricted by soil bacteria.

\section{Characteristics and driving factors of fungal community structure after fire}

The dominant soil fungi orders are Helotiales, Agaricales, and Russulales. Eight weeks after a high intensity fire, the abundance ratios and diversity decreased significantly and the community structure showed significant change from the original fungi to fungi dominated by Archaeorhizomycetales, Helotiales, and Eurotiales. Over time, the community structure enlarged. Thirty years after fire, the fungal community changed to a community dominated by Archaeorhizomycetales, Russulales, and Helotiales. After low/intermediate fire, the abundance ratios and diversity decreased but the community structure was only slightly changed from being dominated by Helotiales, Agaricales, and Russulales to being dominated by Helotiales. With greater recovery time, the bacterial community gradually recovered and was restored to pre-fire levels.

Different species of soil fungi have various survival characteristics and specific relationships with vegetation. Therefore, changes in vegetative cover could be a significant influence on soil fungi. Archaeorhizomycetales was negatively correlated with tree biomass, and positively with herbaceous diversity. Eurotiales and Helotiales are negatively correlated with tree biomass while positive with herbaceous diversity. Agaricales and Russulales show positive correlation with biomass and negative correlation with herbaceous diversity (Fig. 10). Agaricomycetes of the Agaricales phylum and Russula of the Russulales phylum are the main ectomycorrhizal fungi of pines and also able to use saprophytic fungi using litter (Zhang et al. 2016). Archaeorhizomycetales is commonly distributed in the rhizosphere of Pinus, Rhododendron, and other species which can either coexist with mycorrhizal fungi or provide organic matter for saprophytic fungi (Rosling et al. 2011). The mixed forest of Daxing' anling is largely homogeneous plant species dominated by Chinese larch associated with birch and aspen. Their roots are densely distributed in the soil which is rich in organic matter. Agaricales and Russulales fungi multiply rapidly through symbiosis and saprophytic relationship with roots. After fire, most vegetation was killed and roots decreased accordingly. Soil organic matter was largely consumed and further reduced the quantity Agaricales and Russulales due to the loss of nutrients. For low/intermediateseverity fire, the surface vegetation structure had not been greatly changed and recovered quickly, so that the number of Agaricales and Russulales could gradually restore to prefire levels. For high-severity fire, the restoration process of surface vegetation should be: open herb community $\rightarrow$ shrub and grass community $\rightarrow$ mixed forest. Agaricales and Russulales are specific to ecosystems and host habitats and unable to adapt to frequent changes to surface vegetation and failed to restore to pre-fire level. However, Archaeorhizomycetales, due to its powerful adaption capability dominated among soil fungi (Fig. 10).

The influence of the soil environment on soil fungi cannot be ignored. Archaeorhizomycetales is positively correlated with $\mathrm{pH}$, while Helotiales, Agaricales, and Russulales
Fig. 10 Correlation coefficient of soil fungal community and environmental factors $(* * a$ significant difference between the factors at the 0.01 level; *a significant difference between the factors at the 0.05 level)

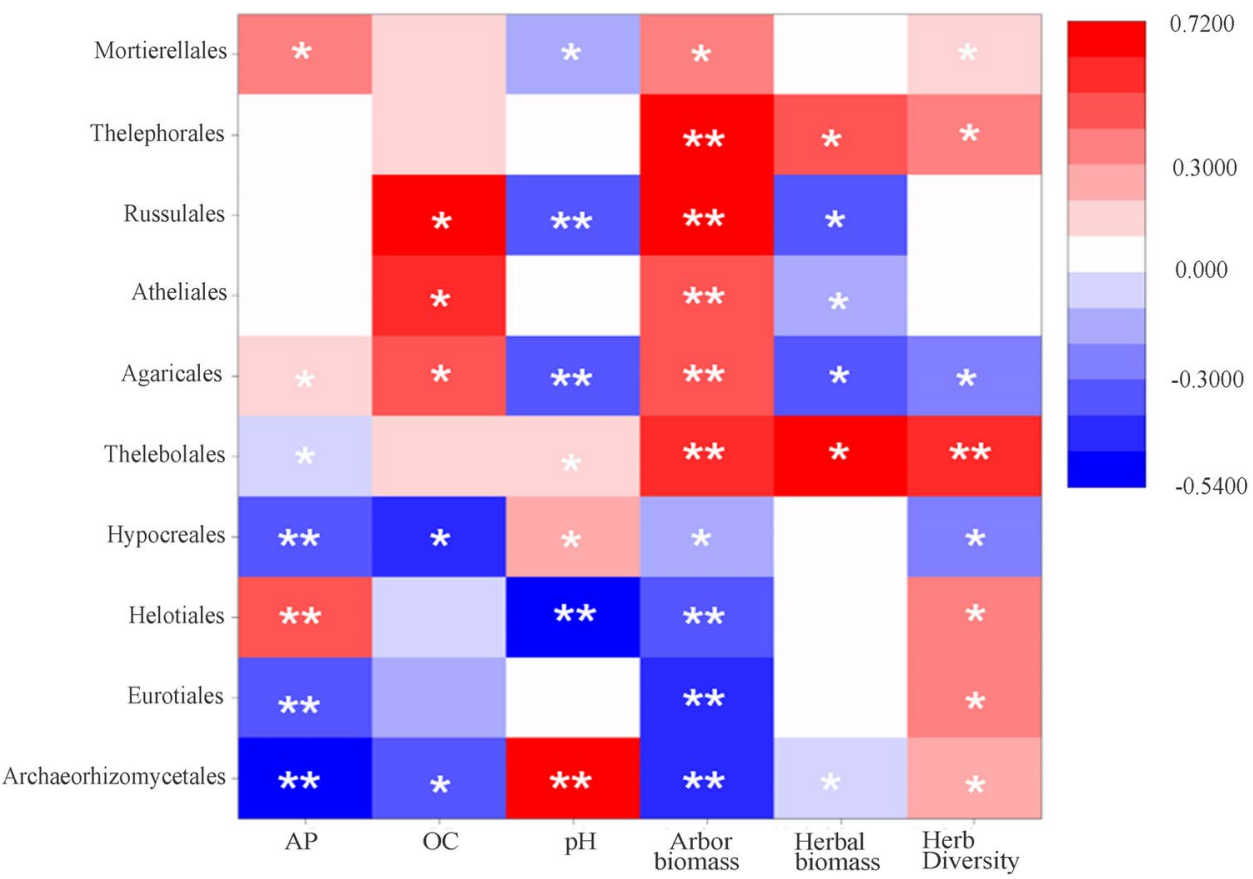


are negatively correlated (Fig. 10). Soil fungi also show a prominent physiological gradient to $\mathrm{pH}$. The optimal $\mathrm{pH}$ for Agaricales and Russulales is 3-5, while the optimal for Archaeorhizomycetales is around 7 (Xiong et al. 2019). Archaeorhizomycetales was negatively correlated with available phosphorous and total organic carbon; Eurotiales was negatively correlated with available phosphorous; Russulales and Agaricales were positively correlated with total organic carbon; Helotiales was positively correlated with available phosphorous (Fig. 10). After fire disturbance, the $\mathrm{pH}$ rose which promoted the growth of Archaeorhizomycetales which grows best in a neutral soil. Organic matter in the soil was consumed by the fire so that the growth of Agaricales and Russulales were significantly reduced due to the lack of saprophytic nutrition. Soil available phosphorous was consumed and reduced by Archaeorhizomycetales and Eurotiales, which dramatically contained the growth of Helotiales.

\section{Prediction of soil functions after fire disturbance}

According to the prediction of PICRUSt2, soil microbe functions related to carbon fixation, cellulose degradation and organic phosphorus hydrolysis were in relatively high abundance. In contrast, hemicellulose and lignin degradation, nitrogen fixation, nitrification and denitrification were low. This indicates that, in the soil of the study area, microbes are capable in decomposing cellulose but weak in decomposing hemicellulose and lignin, and weak in functions related to nitrogen cycling.

The carbon cycling process in the soil occurs with both bacteria and fungi simultaneously. Carbon fixation by the soil converts inorganic carbon to organic carbon, thus enhancing total organic carbon. In the soil of the study area, the Calvin cycle pathway, involving participation of photoautotrophic microorganisms like Cyanobacteria, the 3-hydroxypropionate pathway involving input by Chloroflexi, the anaerobic acetyl-CoA pathway with anaerobic bacteria, and the oxaloacetate pathway involving of symbiotrophism fungi like ectomycorrhizal fungi and arbuscular mycorrhizal fungi, were the main ways to increase total organic carbon (Yuan et al. 2011). The degrading cellulose, hemicellulose and lignin represented microbe capability in decomposing and re-utilizing organic matter in animal and plant residues (Yuan et al. 2011), among which, Acidobacteria helped degrade plant carbon like cellulose and hemicellulose efficiently (Fierer et al. 2007). Actinobacteria played an important role in lignin degradation (Pan et al. 2011). After fire disturbance, the rise of soil $\mathrm{pH}$ led to an increase in the relative abundance of Cyanobacteria, Chloroflexi, and Acidobacteria, which further enhanced microbe carbon fixation and lignin degradation; the relative abundance of Acidobacteria decreased, which weakened microbe capability in degrading cellulose and hemicellulose. In fact, the enhanced capability in carbon fixation and lignin degradation were favorable for total organic carbon accumulation. The forest fire played a positive role in soil carbon cycling.

Soil nitrogen cycling was accomplished by soil bacteria. Soil nitrogen cycle mainly includes nitrogen fixation, nitrification, and denitrification, etc. Nitrogen fixation converts nitrogen in the air into ammonia, which is beneficial for the accumulation of nitrogen in the soil (Sierra 1992; Chen et al. 2006). Nitrogen fixation in the study area soil was achieved through symbiotic nitrogen fixation bacteria like Frankia. Nitrification is an important step for organic nitrogen mineralization, for soil microbes in decomposing and reutilizing nitrogen in animal and plant residues (Weier et al. 1993; Galloway et al. 2004). In the study area, nitrification is mainly achieved by nitrifying bacteria of Nitrospira and Nitrosomonadaceae. Denitrification converts nitrates and nitrites into nitrogen to return it to the atmosphere (Weier et al. 1993; Galloway et al. 2004). In the study area, denitrification is mainly achieved by denitrifying bacteria. Research indicates that most denitrifying bacteria are heterotrophic which take organic matter as carbon and energy sources (Mao and Qi2015). After fire, Frankia decreased due reduction in available phosphorous and weakened nitrogen fixation. The increase in $\mathrm{pH}$ resulted in an increase in nitrifying bacteria such as Nitrospira and Nitrosomonadaceae which enhanced nitrification. The decrease total organic carbon levels resulted in an inadequate supply of denitrifying bacteria, weakening the denitrification effect. The strengthening of soil nitrification and nitrogen fixation were important for the accumulation of nitrogen; the weakening of denitrification reduced nitrogen consumption and fire played a positive role in soil nitrogen cycling.

Organic phosphorus hydrolysis hydrolyzes macromolecular organic phosphorus into available phosphorus that can be directly absorbed by organisms (Podgorskii 1988; Liu et al. 2015). This occurs in both soil bacteria and fungi simultaneously. After fire, soil pH (4.6-5.6) rose slightly but was still weakly acidic. This had little effect on acid phosphatase but and weakened the inhibitory effect of alkaline phosphatase. Overall levels of phosphatase increased, the hydrolysis of organic phosphorus was enhanced, and the availability of phosphorus in the soil was also increased. Fire had positive influence on phosphorus cycling.

\section{Conclusions}

Fire of different intensities has various effects on soil bacterial communities. Severe fires negatively impact soil bacterial communities. Fire changes the nutrients levels, damages original bacterial communities, and replaces them by bacteria with more powerful adaption capabilities. Such kinds 
of changes require at least 30 years to restore to the original communities. Low/intermediate fires enhances diversity and abundances of bacterial communities and optimizes composition by improving the soil environment.

Changes brought by high intensity fires on soil fungal communities are irreversible in the short-term because surface vegetation is destroyed and there is a loss of soil nutrients. This results in the decrease or loss of dominant fungi like Agaricales and Russulales while Archaeorhizomycetales becomes dominant fungi by its strong adaptability. Over time, these changes become worse and are not restored in 30 years. However, low/intermediate-severity fires only affects the environment to a small extent. The relative amounts of Agaricales and Russulales are slightly reduced but are restored essentially after 30 years.

After fire disturbance, soil carbon fixation, lignin degradation, mineralization of organic nitrogen and hydrolysis of organic phosphorus are enhanced, while denitrification is weakened. This positively promotes soil carbon, nitrogen, and phosphorus cycles to some extent.

Acknowledgements We thank the Inner Mongolia Daxing'anling Forest Ecosystem Research Station for support. We thank Yongliang Zhang (Inner Mongolia Daxing' anling Forest Ecosystem Research Station) and Zhenggong Yu (Inner Mongolian University) who helped measure the data.

Open Access This article is licensed under a Creative Commons Attribution 4.0 International License, which permits use, sharing, adaptation, distribution and reproduction in any medium or format, as long as you give appropriate credit to the original author(s) and the source, provide a link to the Creative Commons licence, and indicate if changes were made. The images or other third party material in this article are included in the article's Creative Commons licence, unless indicated otherwise in a credit line to the material. If material is not included in the article's Creative Commons licence and your intended use is not permitted by statutory regulation or exceeds the permitted use, you will need to obtain permission directly from the copyright holder. To view a copy of this licence, visit http://creativecommons.org/licenses/by/4.0/.

\section{References}

Akburak S, Son Y, Makineci E, Meri A (2018) Impacts of low-intensity prescribed fire on microbial and chemical soil properties in a Quercus frainetto forest. J For Res 29(3):687-696

Austin MP, Smith TM (1990) A new model for the continuum concept in Progress in theoretical vegetation science. Vegetatio 83:35-47

Brais S, David P, Ouimet R (2000) Impact of wild fire severity and salvage harvesting on the nutrient balance of jack pine and black spruce boreal stands. For Ecol Manag 137:231-243

Cai YF, Wu YC, Wang SW, Yan XY, Zhu YG, Jia ZJ (2014) Microbial metabolism in typical flooded paddy soils. Acta Microbiol Sin 54(9):1033-1044

Chaudhry V, Rehman A, Mishra A, Chauhan PS, Nautiyal CS (2012) Changes in bacterial community structure of agricultural land due to long-term organic and chemical amendments. Microbial Ecol 64:450-460
Chen F, Zeng D, Zhou B, Singh AN, Fan ZP (2006) Seasonal variation in soil nitrogen availability under Mongolian pine plantations at the Keerqin Sand Lands, China. J Arid Environ 67:226-239

Chen ZJ, Gao SK, Chen Y, He PH, He Q, Qiu Q, Li JY (2020) Effects of short-term fertilization on soil fungal community structure and functional group in Eucalyptus artificial forest. Acta Ecol Sin 40(11):1-9

Elsas JD, Boersma FG (2011) A review of molecular methods to study the microbiota of soil and the microsphere. Eur J Soil Biol 47:77-87

Felske A, Wolterink A, Van-Lis R, Devos WM, Akkermans AD (2000) Response of a soil bacterial community to grassland succession as monitored by $16 \mathrm{~S}$ rRNA levels of the predominant ribo types. Appl Environ Microbiol 66(9):3998-4003

Fierer N, Bradford MA, Jackson RB (2007) Towards an ecological classification of soil bacteria. Ecology 88:1354-1364

Fontaine S, Mariotti A, Abbadie L (2003) The priming effect of organic matter: a question of microbial competition? Soil Biol Biochem 35:837-843

Galloway JN, Dentener FJ, Capone DG, Boyer EW, Howarth RW, Seitzinger SP, Asner GP, Cleveland CC, Green PA, Holland EA, Karl DM, Michaels AF, Porter JH, Townsend AR, Vorosmarty CJ (2004) Nitrogen cycles: past, present, and future. Biogeochemistry 70:153-226

Gholz HL, Wedin DA, Smitherman SM, Harmon ME, Parton WJ (2000) Long-term dynamics of pine and hardwood litter in contrasting environments: towards a global model of decomposition. Glob Change Biol 6:751-765

Han WX, Fang JY, Guo DL, Zhang Y (2005) Leaf nitrogen and phosphorus stoichiometry across 753 terrestrial plant species in China. New Phytol 168:377-385

Holden SR, Rogers BM, Treseder KK (2016) Fire severity influences the response of soil microbes to a boreal forest fire. Environ Res Lett 11:035004

Kaiser K, Wemheuer B, Korolkow V, Wemheuer F, Nacke H, Schoening I, Schrumpf M, Daniel R (2016) Driving forces of soil bacterial community structure, diversity, and function in temperate grasslands and forests. Sci Rep 6:33696

Key CH, Benson NC (2006) Landscape assessment: sampling and analysis methods. USDA Forest Service, Rocky Mountain Research Station General Technical Report, Ogden, UT, USA

Kuramae EE, Gamper HA, Yergeau E, Piceno YM, Brodie EL, Desantis TZ, Andersen GL, Veen JA, Kowalchuk GA (2010) Microbial secondary succession in a chrono sequence of chalk grasslands. ISME J 4(5):711-715

Li MJ, Yu LF, Du MF, Huang ZS, Shi JH (2018) C, N, and P stoichiometry and their interaction with plants, litter, and soil in a Cunninghamia lanceolate plantation with different ages. Acta Ecol Sin 38:7772-7781

Li ZJ, Shen YX, Zhao GJ, Yu ZF, Chen FJ, Xiao GY (2020) Changes of soil fungi and bacteria after forest soil transplantation. Microbiol China 1-13. https://doi.org/10.13344/j.microbiol.china .190948

Liu ZG, Li YC, Zhang SA, Fu YQ, Fan XH, Patel JS, Zhang M (2015) Characterization of phosphate-solubilizing bacteria isolated from calcareous soils. Appl Soil Ecol 96:217-224

Liu GL, Niu SW, Xu JY, Sui SJ, Ye X, Wang N (2019) Effects of optimized $\mathrm{N}$ fertilization on rice soil bacterial diversity of rice crab symbiosis system analyzed by high-throughput sequencing technology. J Jilin Agric Univ 41(6):686-694

Luo ZB, Ma J, Chen F, Li XX, Zhang Q, Yang YJ (2020) Adaptive development of soil bacterial communities to ecological processes caused by mining activities in the loess plateau, China. Microorganisms 8:1-22 
Man SA, Herre EA, Bever JD (2010) Specificity between Neotropical tree seedlings and their fungal mutualists leads to plant-soil feedback. Ecology 91:2594-2603

Mao C, Qi LH (2015) Research advances in forest soil nitrogen transformation and cycling. World For Res 28(2):8-13 (in Chinese)

Mcgroddy ME, Daufresne T, Hedin LO (2004) Scaling of C: N: P stoichiometry in forests worldwide: implications of terrestrial redfield-type ratios. Ecology 85:2390-2401

Mickan BS, Abbott LK, Fan JW (2017) Application of compost and clay under water-stressed conditions influences functional diversity of rhizosphere bacteria. Biol Fertil Soils 54(1):55-70

Pan MF, Jiang M, Zhou ZW (2011) The latest research progress of lignin biodegradation. Mater GUIDE 11(25):372-377 (in Chinese)

Parton W, Silver WL, Burke IC, Grassens L, Harmon ME, Currie WS, King JY, Adair EC, Brandt LA, Hart SC, Fasth B (2007) Globalscale similarities in nitrogen release patterns during long-term decomposition. Science 315:361-364

Podgorskii VS (1988) Leaching of silicon containing rock using Bacillus mucilaginosus. Mikrobiologichesdiizhurnal 50:25-30

Rasche F, Knapp D, Kaiser C, Koranda M, Kitzler B, ZechmeisterBoltenstern S, Richter A, Sessitsch A (2011) Seasonality and resource availability control bacterial and archaeal communities in soils of a temperate beech forest. ISME J 5:389-402

Rosling A, Cox F, Cruz-Martinez K, Ihrmark K, Grelet GA, Lindahl BD, Menkis A, James TY (2011) Archaeorhizomycetes: unearthing an ancient class of ubiquitous soil fungi. Science 333:876-900

Schmidta R, Mitchellb J, Scow K (2019) Cover cropping and no-till increase diversity and symbiotroph: saprotroph ratios of soil fungal communities. Soil Biol Biochem 129:99-109

Shen CC, Xiong JB, Zhang HY (2013) Soil pH drives the spatial distribution of bacterial communities along elevation on Changbai Mountain. Soil Biol Biochem 57:204-211

Shigeto O, Image S, Aiichiro K (2008) Community structure of soil bacteria in a tropical rainforest several years after fire. Microbes Environ 23:49-56

Sierra J (1992) Relationship between mineral N content and N mineralization rate in disturbed and undisturbed soil samples incubated under field and laboratory conditions. Soil Res 30:477-492

Tian Y, Zhang QL, Liu X, Meng M (2018) Stem radius variation in response to hydro-thermal factors in larch. Forests 9(10):602

Van SO, Doamba SW, Corre MD, Veldkamp E (2019) Impacts of burning on soil trace gas fluxes in two wooded savanna sites in Burkina Faso. J Arid Environ 165:132-140
Villadas PJ, Díaz S, Rodríguez A, Arco-Aguilar M, Fernandez-Gonzalez A, Perez-Yepez J, Arbelo C, Gonzalez-Mancebo JM, Fernandez-Lopez M, Leon-Barrios M (2019) The soil microbiome of the laurel forest in Garajonay National Park (La Gomera, Canary Islands): comparing unburned and burned habitats after a wildfire. Forests 10:1051

Vries FT (2012) Abiotic drivers and plant traits explain landscape-scale patterns in soil microbial communities. Ecol Lett 15(11):1230-1239

Wallenius TH, Kuuluvainen T, Vanha-Majamaa I (2004) Fire history in relation to site type and vegetation in Vienansalo wilderness in eastern Fennoscandia, Russia. Can J For Res 34:1400-1409

Wang XG, Li H, Bezemer TM, Zhanqing H (2016) Drivers of bacterial beta diversity in two temperate forests. Ecol Res 31:57-64

Wang XG, Sun RB, Tian YP, Guo K, Sun HY, Liu XJ, Chu HY, Liu BB (2020) Long-term phytoremediation of coastal saline soil reveals plant species-specific patterns of microbial community recruitment. Ecol Evolut Sci 5:e00741-19

Weier K, Macrae I, Myers R (1993) Denitrification in a clay soil under pasture and annual crop: estimation of potential losses using intact soil cores. Soil Biol Biochem 25:991-997

Wu QZ, Lu J, Ji CS (2020) Effects of undergrowth vegetation management measures on the soil bacterial community structure of large diameter timber plantation of Cunningham lanceolate. Chin J Appl Ecol 31(2):407-416 (in Chinese)

Xiong D, Ou J, Li LP, Yang ST, He YJ, Li ZC (2019) Diversity of Rhododendron rhizome fungi in Pinus massoniana-Rhododendron community in central Guizhou. J Southwest Univ 41:21-29 (in Chinese)

Yuan HZ, Qin HL, Liu SL, Nie SA, Wei WX, Wu JS (2011) Advances in research of molecular ecology of carbon fixation microorganism. Sci Agric Sin 44:2951-2958

Zhang YH, Jian N, Tang FP (2016) The effects of different human disturbance regimes on root fungal diversity of Rhododendron ovatum in subtropical forests of China. Can J For Res 47:659-666

Zhang H, Yue Y, Song XM (2020) Hulunbeier climate change impact on forest grassland fire and future trend analysis. J Nanjing For Univ (Nat Sci Edn) 44(5):222-230 (in Chinese)

Publisher's Note Springer Nature remains neutral with regard to jurisdictional claims in published maps and institutional affiliations. 